\title{
INSECTICIDAL ACTIVITY OF EXTRACTS DERIVED FROM DIFFERENT PARTS OF THE MANGROVE TREE RHIZOPHORA MUCRONATA (RHIZOPHORACEAE) LAM. AGAINST THREE ARTHROPODS
}

\author{
J.M. Kabaru and L. Gichia \\ Department of Zoology, University of Nairobi, P.O.Box 30197, Nairobi, Kenya.
}

\begin{abstract}
The insecticidal and antifeedant activity of extracts derived from different parts of the mangrove tree Rhizophora mucronata (Rhizophoraceae) Lam. is reported. The 70\% ethanol extracts of leaves, bark, stem wood and pith were tested for toxicity against adults of the desert locust Schistocerca gregaria (Forskal), the $2^{\text {nd }}$ instar larvae of Aedes aegypti $(L$.$) and the 1^{\text {st }}$ instar larvae of the brine shrimp Artemia salina (Leach). Antifeedant activity of the extracts was assessed through tests conducted on S. gregaria adults by the paper feeding protection bioassay. In tests carried out on A. aegypti mosquito larvae, bark and pith extracts showed high toxicity with 48 hour $L C_{50}$ 's of 157.4 ppm and 168.3 ppm respectively. Stem wood extracts had low activity with an $L C_{50}$ of 1003.4 ppm while leaf extracts did not exhibit toxic effects at a concentration of $1000 \mathrm{ppm}$. A similar trend in activity was observed with antifeedant tests conducted on the desert locust S. gregaria and on toxicity tests carried out on A. salina larvae. The bulk of the active compounds are sequestered in the bark, pith and stem wood with the least being found in the leaves. The results indicate that $R$. mucronata is a potential source of botanical insecticides(s).
\end{abstract}

Key words: Botanical insecticides, mangrove, Rhizophora mucronata

\section{INTRODUCTION}

Insect pests have mainly been controlled with synthetic insecticides in the last fifty years. Most insecticidal compounds fall within four main classes, the organochlorines, organophosphates, the carbamates and pyrethroids. Out of these the major classes in use today are organophosphates and carbamates $(1,2)$. There are problems of pesticide resistance and negative effects on non-target organisms including man and the environment $(3,4,5)$. The use of organochlorine insecticides has been banned in developed countries and alternative methods of insect pest control are being investigated (4). Botanicals are a promising source of pest control compounds.

The pool of plants possessing insecticidal substances is enormous (6). These have generated extraordinary interest in recent years as potential sources of natural insect control agents. Today over 2000 species of plants are known that possess some insecticidal activity (7). The first insecticides to be used by man were from plants, the biological activities of which were known from the earliest recorded times (8). In the middle of the $17^{\text {th }}$ century, pyrethrum, nicotine, and rotenone were recognised as effective insect-control agents (9).
The most economically important of the natural plant compounds used in commercial insect control are the pyrethrins from the flower heads of pyrethrum Chrysanthemum cinerariaefolium Vis. (10). Despite the relative safety of well known botanical insecticides, most of these substances have their drawbacks hindering large scale application. Pyrethrins are unstable in light and are rapidly metabolised thus limiting their potency and application (11). These limitations gave impetus for the synthesis of active analogues, termed pyrethroids (12). Nicotine, isolated from a number of species of Nicotiana is insecticidal), but its use in insect control has dropped steadily because of the high cost of production, disagreable odour, extreme mammalian toxicity, instability in the environment and limited insecticidal activity (13). Rotenone is unstable and very toxic to fish (14). Further, several insects have exhibited resistance to pyrethroids (15). For these reasons, the search for new safer and more effective insecticides from plants is justified. Indeed, research in this area has led to the discovery of substances with interesting activities on insects. The substances include insect growth regulators/inhibitors and antifeedants $(16,17)$.

The insect growth regulators/inhibitors specifically affect growth and development of insects. These compounds 
include mimics and inhibitors of two groups of insect hormones, namely the juvenile hormones and the moulting hormones $(18,19)$. Antifeedants are substances which when tasted by insects, result either temporarily or permanently, depending on potency, in the cessation of feeding (20).

The botanical insecticides are generally pest-specific and are relatively harmless to non-target organisms including man. They are also biodegradable and harmless to the environment (17). Furthermore, unlike conventional insecticides which are based on a single active ingredient, plant derived insecticides comprise an array of chemical compounds which act concertedly on both behavioural and physiological processes. Thus the chances of pests developing resistance to such substances are less likely (16). One plant species may possess substances with a wide range of activities, for example extracts from the the neem tree Azadirachta indica are antifeedant, antioviposition, repellent and growth-regulating (21). In contrast, the toxicity of conventional synthetic insecticides is mainly restricted to neuro-muscular function (1).

Conventional synthetic insecticides require special safety procedures and equipment during production and application (1). Despite precautions, exposure to humans, the environment (4) and food (5). The synthetic insecticides are expensive and have in many cases only produced moderate results along with major ecological damage (4). In contrast, the low toxicity of botanical insecticides makes processing and application of the product inexpensive. In many cases, the materials are locally available and affordable (22).

Considering the large number of plants that are reputed to possess some form of insecticidal activity, it is a pity that only a few have been scientifically evaluated. A good example of a plant with reputed insect resistant properties is the mangrove tree Rhizophora mucronata (Rhizophoraceae) Lam. Which grows in the salty muddy shores of the coast of East Africa and various parts of Asia (10). The tree grows to a height of 3-12 metres and has stilt roots. It is often the dominant species on the edge of mangrove swamps (23). From time immemorial poles of the mangrove tree $R$. mucronata have been used to construct dhows and houses and baskets in coastal areas $(23,24)$. The poles made from the tree are known to be highly resistant to rotting and even attack by arthropods e.g. insects (6). The tree is a good source of tannins for the treatment of leather (10). Although this information has been available for hundreds of years and hence the popularity of the mangrove for building purposes, there is no scientific investigation to determine the part of the tree which has toxic activity against insects or the mode of action of the active substances.
Based on the foregoing, we sort to scientifically evaluate the insecticidal activity of the mangrove $R$. mucronata and the distribution of the active substances within the tree with a view to generating data that will lay the foundation for future research work in fractionation, structural determination and application.

\section{MATERIALSAND METHODS}

\section{Preparation of mangrove extracts}

Rhizophora mucronata (Lam.) was collected from the Kenya coast near Mombasa with the assistance of the Herbarium, Department of Botany, University of Nairobi. The leaves, bark, stem wood and pith were dried at $30^{\circ} \mathrm{C}$ for 12 hours and pulverized to powder separately in a hammer mill. One hundred grams of powder from each of the plant parts were then extracted three times with $500 \mathrm{ml}$ of aqueous $70 \%$ ethanol. After 12 hours, the supernatants were decanted, filtered and dried in a rotary evaporator at $40^{\circ} \mathrm{C}$ for 30 minutes. The dry extracts were kept desiccated at $4^{\circ} \mathrm{C}$.

\section{Experimental organisms}

Five-day-old male desert locusts Schistocerca gregaria (Forskal) used in this study were reared in the Department of Zoology, University of Nairobi as described by HunterJones, (25). The insects were fed on wheat bran and wheat seedlings. The gregarious colony was reared under crowded conditions in a light:dark regime of $12 \mathrm{~L}: 12 \mathrm{D}$ at a temperature of $29 \pm 1{ }^{\circ} \mathrm{C}$ and a relative humidity of $60 \%$. Second instar Aedes aegypti (L.) larvae for the larvicidal assays were obtained from a colony maintained in the Department of Zoology. The mosquito larvae were fed on dog biscuit, while the adults were reared on saturated sucrose solution and allowed to take blood meals from the blood vessels of rabbit ears ad libitum. The mosquito eggs were hatched in $0.08 \% \mathrm{NaCl}$ solution (26). Eggs of the brine shrimp Artemia salina (Leach) were obtained from Interpet ${ }^{\circledR}$ Ltd. England. First instar larvae for bioassays were obtained by hatching the eggs in a 3.3\% solution of natural marine salt (27). The larvae were fed brewer's yeast. Both the A. aegypti and A. salina larvae were maintained at $25 \pm 2^{\circ} \mathrm{C}$.

\section{Larval toxicity tests}

All the extracts were tested for the presence of biologically active substances against the $2^{\text {nd }}$ instar larvae of $A$. aegypt $i$ and $1^{\text {st }}$ instar larvae of $A$. salina. The A. aegypti tests were performed in $40 \mathrm{ml}$ of $0.08 \% \mathrm{NaCl}$ solution (26) contained 
in $100 \mathrm{ml}$ petri dishes as described by (28). The test material was dissolved in $70 \%$ ethanol so that the final volume did not exceed $0.1 \mathrm{ml}$. Larval food consisted of $0.05 \mathrm{~g}$ of brewer's yeast per dish. The number of larvae in each dish was 20 . Controls in all cases received $0.1 \mathrm{ml}$ of $70 \%$ ethanol. After 48 hours, dead larvae were removed and counted. The extracts were tested at doses of 100,140,180, 220, 260 and $300 \mathrm{ppm}$. In a similar experiment, the toxicity of extracts to the $1^{\text {st }}$ instar larvae of $A$. salina was assessed in $3.3 \%$ solution of natural marine salt (27). The extracts were tested at doses of 60, 100, 140, 180 and 220 ppm Each experiment was replicated three times, and the data subjected to probit (29) and regression analysis (30) to determine the $\mathrm{LC}_{50}$ 's of the extracts.

\section{Antifeedant tests}

All the extracts were assessed for antifeedant activity against the desert locust by the paper feeding protection bioassay. Fifty microlitres of test solution in $70 \%$ ethanol were applied to Whatman ${ }^{\circledR}$ number 1 qualitative grade filter paper squares measuring $2 \times 2 \mathrm{~cm}$ impregnated with $0.25 \mathrm{M}$ sucrose and dried at $40^{\circ} \mathrm{C}$ for 30 minutes. Control papers were treated with $50 \mu \mathrm{l}$ of $70 \%$ ethanol. The papers were then presented to 24-hour starved five-day-old male desert locusts in one cage of dimensions 43 x 43 x $50 \mathrm{~cm}$ (choice test). The ratio of the number of paper squares to locusts was 3:1. For tests on bark and pith extracts, there were 21 locusts in the cage. In the case of tests on stem extract there were 24 locusts in the cage. Bark and pith extracts were tested at concentrations of 100, 200, 300, 400, 500 and $600 \mathrm{ppm}$, while stem extracts were tested at concentrations of 400, 500, 600, 700, 800, 900 and 1000 ppm. After 24 hours, the papers were retrieved and the percentage feeding protection calculated according to the following formula:

Percentage feeding protection $=\frac{(\mathrm{C}-\mathrm{t})}{\mathrm{T}} \times 100$

Where:

$\mathrm{C}=$ Area of one set of control papers consumed $\left(\mathrm{mm}^{2}\right)$ $\mathrm{t}=$ Area of one set of treated papers consumed $\left(\mathrm{mm}^{2}\right)$ $\mathrm{T}=$ Area of one set of intact papers $\left(\mathrm{mm}^{2}\right)$

The experiment was replicated three times. The antifeedant $\mathrm{ED}_{50}$ of each extract was then estimated by subjecting the percentage feeding protection data to probit (29) and regression analysis (30) to determine the $\mathrm{ED}_{50}$ 's of the extracts.

\section{Tests for direct toxicity on locusts}

All the extracts were assessed for direct toxicity against the desert locust. Solutions of mangrove extracts for injection were prepared in $60 \%$ aqueous ethanol. Locusts were injected with $5 \mu \mathrm{l}$ of the solutions in the inter-segmental membrane between the $2^{\text {nd }}$ and $3^{\text {rd }}$ sternites with a microlitre syringe fitted with a gauge 26 hypodermic needle. Control locusts were injected with $5 \mu$ l of $60 \%$ ethanol. Ten locusts were used for each dose tested and the experiment was replicated three times. For tests on bark and pith extracts, the doses used were 50, 100, 150, 200, 250 and $300 \mathrm{ppm}$. In the case of tests on stem extracts, the doses used were 400, 500, 600, 700, 800, 900 and 1000 ppm. After 48 hours, dead locusts counted and the data subjected to probit (29) and regression analysis (30) to determine the $\mathrm{LD}_{50}$ 's of the extracts.

\section{RESULTS}

The amounts of dry $70 \%$ ethanol soluble material from 100 $\mathrm{g}$ of the different parts of $R$. Mucronata were varied (Table 1). The highest weight was obtained from pith, which produced $4.60 \pm 0.26 \mathrm{~g}$. Leaves produced $4.12 \pm 0.25 \mathrm{~g}$ while bark and stem wood produced $3.22 \pm 0.17 \mathrm{~g}$ and $1.31 \pm 0.12 \mathrm{~g}$ respectively. These weights were significantly different (ANOVA F3, 8(1)=141.028, $\mathrm{P}=0.000$ ).

Table 1. The weight of dry $70 \%$ ethanol soluble material from $100 \mathrm{~g}$ of different parts of Rhizophora mucronata

\begin{tabular}{ll} 
Part of plant & $\begin{array}{l}\text { Weight of extract } \\
(\mathrm{g} \pm \text { S.E.M. } \mathrm{n}=3)\end{array}$ \\
\hline Pith & $4.60 \pm 0.26$ \\
Leaves & $4.12 \pm 0.25$ \\
Bark & $3.22 \pm 0.17$ \\
Stem wood & $1.31 \pm 0.12$
\end{tabular}

The results of the toxicity of $R$. mucronata bark, pith and stem wood extracts to the $2^{\text {nd }}$ instar larvae of $A$. aegypti and the $1^{\text {st }}$ instar larvae of $A$. salina are presented in Table 2. The equations of the regression lines from probit mortality versus log dosage plots and the lower and upper confidence limits of the $\mathrm{LC}_{50}$ 's of each extract are also shown on Table 2. In this test, bark and pith extracts showed high toxicity with $\mathrm{LC}_{50 \text { 's }}$ of $157.4 \mathrm{ppm}$ and $168.3 \mathrm{ppm}$ respectively against $A$. aegypti larvae. Extracts of stem wood had low activity with an $\mathrm{LC}_{50}$ of $1003.4 \mathrm{ppm}$. Toxicity of bark, pith 
and stem wood extracts of $R$. mucronata to $A$. salina larvae is presented in Table 2. The equations of the regression lines from probit mortality versus log dosage plots and the lower and upper confidence limits of the $\mathrm{LC}_{50}$ 's of each extract are also shown on Table 2. Similarly, bark and pith extracts showed high toxicity with $\mathrm{LC}_{50 \text { 's }}$ of $87.3 \mathrm{ppm}$ and $65 \mathrm{ppm}$ respectively against $A$. salina larvae. Extracts of stem wood had low activity with an $\mathrm{LC}_{50}$ of $745.4 \mathrm{ppm}$. The $\mathrm{LC}_{50}$ of leaf extracts could not be determined because no mortality was observed even at the highest concentration of 1000 ppm used.

Table 2. Toxicity of Rhizophora mucronata bark, pith and stem wood extracts to the larvae of Aedes aegypti and Artemia salina

\begin{tabular}{|c|c|c|c|c|c|c|c|}
\hline \multirow[t]{2}{*}{$\begin{array}{l}\text { Part of } \\
\text { plant }\end{array}$} & \multirow[t]{2}{*}{$\begin{array}{l}\text { Equation of } \\
\text { regression line }\end{array}$} & \multirow[t]{2}{*}{ R-Sq. (\%) } & \multirow[t]{2}{*}{$\begin{array}{l}48 \text { hour } \\
\text { LC50 (ppm) }\end{array}$} & \multicolumn{2}{|c|}{$\begin{array}{l}\text { 95\% C.L. of } \\
\text { LC50 (ppm) }\end{array}$} & \multirow[t]{2}{*}{ t-Value } & \multirow[t]{2}{*}{ d.f. } \\
\hline & & & & Lower & Upper & & \\
\hline \multicolumn{8}{|c|}{ A. aegypti bioassay } \\
\hline Bark & $Y=-17.85+10.40 x$ & 92.5 & 157.4 & 74.8 & 331.2 & $7.031 *$ & 4 \\
\hline Pith & $Y=-23 \cdot 34+12.73 x$ & 93.1 & 168.3 & 72.6 & 390.4 & $6.360 *$ & 3 \\
\hline Stem wood & $Y=-14.96+6.65 x$ & 98.6 & 1003.4 & 637.5 & 1579 & $\begin{array}{r}14.012 \\
*\end{array}$ & 3 \\
\hline \multicolumn{8}{|c|}{ A. salina bioassay } \\
\hline Bark & $Y=-9.75+7.60 x$ & 91.6 & 87.3 & 50.4 & 111.5 & $5.70 *$ & 3 \\
\hline Pith & $Y=-11.19+8.19 x$ & 91.0 & 65 & 39.3 & 228.8 & $5.52 *$ & 3 \\
\hline Stem wood & $Y=-14.36+6.74 x$ & 99.47 & 45.4 & 583.6 & 952.6 & $26.29 *$ & 4 \\
\hline
\end{tabular}

Table 3 shows the toxicity of bark, pith and stem wood extracts of $R$. mucronata to $S$. gregaria adults and the equations of the regression lines from probit mortality versus log dosage plots and the lower and upper confidence limits of the $\mathrm{LD}_{50}$ 's of each extract. In this test, bark and pith extracts showed high toxicity with $\mathrm{LD}_{50 \text { 's }}$ of $337.4 \mathrm{ppm}$ and 287.7 ppm, respectively. As was the case in the $A$. salina and $A$. aegypti larvae bioassays, stem wood extracts had low activity with an $\mathrm{LD}_{50}$ of $1013.4 \mathrm{ppm}$. Leaf extracts were not toxic to $S$. gregaria.

Table 3. Toxicity of bark, pith and stem wood extracts of Rhizophora mucronata to adults of Schistocerca gregaria.

\begin{tabular}{|c|c|c|c|c|c|c|}
\hline \multirow[t]{2}{*}{$\begin{array}{l}\text { Part of } \\
\text { plant }\end{array}$} & \multirow[t]{2}{*}{$\begin{array}{l}\text { Equation of } \\
\text { regression line }\end{array}$} & \multirow[t]{2}{*}{ R-Sq.(\%) } & \multirow[t]{2}{*}{$\begin{array}{l}48 \text { hour } \\
\text { LC50 (ppm) }\end{array}$} & \multicolumn{2}{|c|}{$\begin{array}{l}95 \% \text { C.L. of } \\
\text { LC50 (ppm) }\end{array}$} & \multirow[t]{2}{*}{$\mathrm{t}$-Value } \\
\hline & & & & Lower & Upper & \\
\hline Bark & $\mathrm{Y}=-3.52+3.37 \mathrm{x}$ & 96.8 & 337.4 & 194.6 & 584.8 & $9.536 *$ \\
\hline Pith & $Y=-1.59+2.68 x$ & 99 & 287.7 & 222.1 & 372.6 & $19.447 *$ \\
\hline Stem wood & $Y=-10.54+5.17 x$ & 99.3 & 1013.4 & 800 & 1284 & $27.530 *$ \\
\hline
\end{tabular}

The antifeedant activity of bark, pith and stem wood extracts of $R$. mucronata to $S$. gregaria adults are presented in Table 4. The equations of the regression lines from probit feeding protection versus log dosage plots and the lower and upper confidence limits of the $\mathrm{ED}_{50}$ 's of each extract are shown. The highest antifeedant activity was observed in bark and pith extracts with $\mathrm{ED}_{50 \text { 's }}$ of $191.7 \mathrm{ppm}$ and 188.7 ppm respectively. In this bioassay, the trend of activity in the four extracts was similar to that observed in the toxicity tests. Stem wood extracts had low antifeedant activity with an $\mathrm{ED}_{50}$ of $578 \mathrm{ppm}$. Extracts of the leaves did not show antifeedant action even at the highest concentration of $1000 \mathrm{ppm}$.

Table 4. Antifeedant activity of bark, pith and stem extracts of Rhizophora mucronata to adults of Schistocerca gregaria.

\begin{tabular}{llrrrrrr}
\hline $\begin{array}{l}\text { Part of Equation of } \\
\text { plant } \\
\text { regression line }\end{array}$ & R-Sq.(\%) $\begin{array}{l}\text { 48 hour } \\
\text { LC50 }(\mathrm{ppm})\end{array}$ & $\begin{array}{l}\text { 95\% C.L. of } \\
\text { LC50 }(\mathrm{ppm})\end{array}$ & t-Value & d.f. \\
& & \multicolumn{7}{c}{ Lower } & Upper \\
\hline Bark & $\mathrm{Y}=-4.61+4.21 \mathrm{x}$ & 60.8 & 191.7 & 19.2 & 1913 & 2.491 & 4 \\
Pith & $\mathrm{Y}=-7.13+5.33 \mathrm{x}$ & 79.9 & 188.7 & 44.7 & 795.3 & 3.983 & 4 \\
Stem & $\mathrm{Y}=-22.15+9.83 \mathrm{x}$ & 78.6 & 578 & 126.3 & 2645 & $4.280 *$ & 5 \\
\hline * Significant at $\mathrm{P}<0.05$ & & & & & &
\end{tabular}

\section{DISCUSSION}

The results of the present study are interesting. The findings indicate the importance of traditional knowledge in science. The bark of Rhizophora mucronata has been shown to possess insecticidal and insect repellent components and these protect the wood from insect damage. The wood itself is strong and in addition possesses insecticidal and insect repellent compounds. The soft pith, which would normally be an easy target to pest damage has high insecticidal and insect repellent activity which protects the strong wood from pest damage. Some of the compounds known to be present in mangrove bark are tannins and these are used for treating leather (10). It would be interesting to investigate whether the insecticidal and insect repellent compounds in mangrove are tannins or other classes of compounds. Such studies could also be extended to cover other species of mangrove trees.

A few suggestions can be made from the results of the present study regarding the pest resistant qualities of mangrove. The high yields of active material from the bark is encouraging. During the preparation of mangrove poles, the bark is normally peeled off. Since the yield of active substances is high, it would be possible to produce enough quantities for field application in farms especially at the coast. Another advantage of extracting the material from bark is that this part of the plant is easy to process during extraction due to its softness. The results indicate that the mangrove poles would be resistant to terrestrial insect pests and marine crustaceans. Since mangrove poles are used for constructing boats and houses, it would be interesting to test the extracts against the main pests of wood in the terrestrial environment such as termites and fungi. From the results obtained in this study, it is suggested that future studies concentrate on the activity 
of the bark. This part is easily available by peeling, without destroying the poles.

Today, the environmental safety of an insecticide is considered to be of paramount importance. An insecticide does not have to cause high mortality on target organisms in order to be acceptable. Antifeedant and growth inhibiting activity reduces pest damage to products even without killing the pest. Further, in the long run, populations are reduced through disrupted metamorphosis or reduced fecundity (21). This antifeedant and growth-inhibiting activity can therefore be incorporated into other insect control techniques in the strategy of integrated pest management (IPM). It would be interesting to investigate whether Rhizophara mucronata contains substances similar to the antifeedant and growth inhibiting compounds present in the fruits of Azadirachta indica $(3,21)$ and Melia volkensii $(28,31)$. It would also be important to test for the toxicity of these mangrove extracts on mammals and other non-target organisms. The following conclusions can be made from the results of this study. Rhizophora mucronata bark, pith and stem extracts have toxic effects on the larvae of Aedes aegypti and Artemia salina larvae and adults of Schistocerca gregaria. In addition, these extracts have antifeedant effects on the adults of Schistocerca gregaria. The bark and pith extracts of mangrove have highest insectidical and antifeedant activity.

\section{ACKNOWLEDGEMENTS}

The authors acknowledge the assistance provided by the Departments of Botany and Zoology, University of Nairobi and the German Academic Exchange Service (DAAD) for funding part of the study.

\section{REFERENCES}

1. Ware, G.W. Pesticides: Theory and application. Thompson publications, Fresno, California. 1982, 308 pp.

2. Dorow, E. Present practices of controlling desert locust outbreaks. In: New strategies for locust control. Ed: Rembold, H. ATSAF. Bonn. 1993, 89 pp pp 7-8.

3. Rembold, H. Secondary plant compounds in insect control with special reference to azadirachtins. Advances in Invertebrate reproduction. 1984, 3: 481491.

4. Franzen, H. Need for development of new strategies for locust control. In: New strategies for locust control. Ed: Rembold, H. ATSAF. Bonn. 1993, 89 pp. 9-13.

5. FAO. Pesticide residues in food. Report no. 116. 1992, $146 \mathrm{pp}$.
6. Jacobson, M. Insecticides from plants: A review of the literature, 1954-1971. Agricultural Handbook 461, U.S Department of Agriculture, Washington, D.C. 1975a, $138 \mathrm{pp}$

7. Jacobson, M. Botanical pesticides, past present and future. In: Insecticides of plant origin. (Ed. Arnason, J.T.). Proceeding of the American Chemical Society, Washington, D.C. 1989, pp 1-10.

8. Smith, A.E. and D.M. Secoy. Forerunners of pesticides in classical Greece and Rome, J.Agric. Food Chem. 1975, 23:1050-1055.

9. Crosby, D.G. Natural pest control agents (Ed. Crosby, D.G.). Proceeding of the American Chemical Society, Washington, D.C. 1966, pp 1-16.

10. Schery, R.W. Plants for man. Publ. George Allen and Unwin Ltd., London. 1954, 564 pp.

11. Casida, J.E. Development of synthetic insecticides from natural products: case history of pyrethroids from pyrethrins. In: Natural products for innovative pest management (Ed. Whitehead, D.L. and Bowers W.S.) Publ. Pergamon Press, New York, 1983, 109-125.

12. Yamamoto,I. Mode of action of pyrethroids, nicotenoids and rotenoids. Ann. Rev. Entomol. 1970, 15: 257.

13. Schmeltz, I. Nicotine and other tobacco alkaloids. In: Naturally occurring pesticides. (Ed. Jacobson, M. and Crosby, D.G.) Marcel Dekker, New York. 1971, 326 pp. 99-136.

14. Peveling, R., Weyrich, J. and P. Muller. Side-effects of botanicals, insect growth regulators and entomopathogenic fungi on epigeal non-target arthropods in locust control.In: New trends in locust control. Eds. Krall, S. and Wilps, H., GTZ, Eschborn, 1994, 214 pp. 147-176.

15. Corbett, J.R., Wright, K. and A. Baillie. The biochemistry and mode of action of pesticides. 2nd edition. Academic Press, New York and London. 1984, $314 p p$

16. Saxena R.C. Antifeedants in tropical pest management. Insect Sci. Applic. 1987, 8: 731-736.

17. Rembold H. Advances in invertebrate reproduction. Elsevier Sceince Publishers. 1994, 3: 481-491.

18. Jacobson, M. Naturally occurring insect growth regulators III. Echinolone, a highly active juvenile hormone mimic from Echinaceae augustifolia roots. Lloydia, 1975b, 38: 473-476.

19. Bowers, W.S., Ohta, T. Cleere, J.S. and P.A. Marsella. Discovery of insect anti-juvenile hormones in plants. Science. 1976, 193: 542. 
20. Kubo, I. and K. Nakanishi. Insect repellants and antifeedants from African plants. In: Host plant resistance to pests. (Ed. Hedin, P.A.) American Chemical Society, Washington, D.C. 1977, 157 pp. 165178.

21. Schmutterrer, $\mathrm{H}$. The neem tree Azadirachta indica A. Juss. and other Meliaceous plants. VCH Publishers, Weinheim, Germany. 1995, 696 pp.

22. Childs F.J., Chamberlain, J.R., Antwi, E.A., Daniel J. and P.J.C. Harris. Improvement of neem and its potential benefits to poor farmers. Department of International Development. U.K. 2001, 32 pp.

23. Beentje, H.J. Kenya trees and lianas. National Museums of Kenya, Nairobi. 1994, 722 pp. 144-146.

24. Schmutterer, H. Plants of East Africa with special reference to Kenya. TZ- Verlagsgesellschaft MBH Germany. 1976, 372 pp, 110-111.

25. Hunter-Jones, P. Rearing and breeding locusts in the laboratory. Antilocust research centre, London. 1966, $12 \mathrm{pp}$.

26. Zebitz, C.P.W. Effects of some crude and azadirachtinenriched Neem (Azadirachta indica) seed kernel extracts on larvae of Aedes aegypti. Entomologia Exp. 1984, 35: 11-16.

27. Meyer, B.N., Ferrigni, N.R., Putnam, J.E., Jacobsen, L.B., Nichols, D.E. and J.L. McLaughlin. Brine shrimp: A convenient general bioassay for active plant constituents. Planta medica. 1982, 45: 31-34.

28. Mwangi, R.W. and H. Rembold. Growth inhibiting and larvicidal effects of Melia volkensii extracts on Aedes aegypti larvae. Ent. Exp. Appl. 1988, 46: 103-108.

29. Finney, D.J. Probit analysis. Cambridge University Press. 1952, 318 pp.

30. Zar, J.H. Biostatistical analysis. 2nd Edition. PrenticeHall International, London. 1984, 718 pp.

31. Kabaru, J.M. A toxicological study of Melia volkensii fruit extracts on Locusta migratoria migratoriodes. Ph.D. Thesis, University of Nairobi. 1996, 144 pp. 